\title{
ACERCAMIENTO INICIAL A LA PROTECCIÓN DE LOS INTERESES TRANSINDIVIDUALES EN EL CÓDIGO Modelo de Procesos Colectivos PARA IBEROAMÉRICA*
}

Rafael Bellido Penadés***

\begin{abstract}
Resumen
Este trabajo tiene como principal objetivo realizar un estudio de la pluralidad de normas procesales contenidas en el Código Modelo de Procesos Colectivos para Iberoamérica relativas a instituciones procesales muy diversas: las diversas clases de intereses protegidos, las distintas acciones ejercitables en defensa de derechos e intereses supraindividuales e individuales homogéneos, los sujetos a los que se atribuye legitimación para su ejercicio, el tribunal competente para su conocimiento, los requisitos de la demanda colectiva, las especialidades procesales introducidas respecto del proceso de declaración, o con relación a la liquidación y ejecución de la sentencia, y las relaciones entre las acciones colectivas y las acciones individuales en cuestiones como la acumulación de procesos o la cosa juzgada.
\end{abstract}

Ese estudio se realiza con el fin de descubrir los avances y, en su caso, aspectos susceptibles de mejora en el Código Modelo, así como de realizar algunas propuestas de mejora.

Palabras clave: Código Modelo de Procesos Colectivos, derechos supraindividuales, intereses individuales, acciones colectivas, tutela judicial.

Fecha Recibido: abril 3 de 2014 • Fecha Aceptado: julio 14 de 2014

* Artículo inédito.

** Profesor Titular de Derecho Procesal, Universidad de Valencia (España). Ex Letrado del Tribunal Constitucional. 


\begin{abstract}
This work has as main objective to conduct a study of the plurality of procedural rules contained in the Collective Process Model Code for Latin America on a variety of procedural institutions: the different kinds of interests protected, exercisable actions in advocacy of supra-individual interests and interest homogeneous individual, subjects to which legitimation for their exercises, the competent court for its decision, the requirements of the Class, introduced procedural specialties regarding the declaration process, or in connection with the liquidation and execution of the judgment, and the relationship between collective action and individual action on issues such as process accumulation or res judicata.

This study was performed in order to discover progress and, where appropriate, areas for improvement in the Model Code and to make some suggestions for improvement.
\end{abstract}

Key words: Model Code of Collective Processes, supra individual rights, individual interests, collective actions, legal protection.

\title{
INTRODUCCIÓN
}

En la sociedad actual se producen comportamientos o conductas que no tienen una mera dimensión meramente individual, ya que tienen entidad suficiente como para afectar a pluralidad de personas que se encuentran en una posición similar, lesionando o afectando por tanto dichas conductas a derechos e intereses que son comunes a grupos, categorías o clases de personas. Sería el caso, en palabras de la Exposición de Motivos del Código Modelo de Procesos Colectivos para Iberoamérica ${ }^{1}$, "de los intereses de los consumidores, de (a) la protección del ambiente, de los usuarios de servicios públicos, de los inversores, de los beneficiarios de la Previsión Social y de todos aquellos que integran una comunidad compartiendo sus necesidades y sus anhelos".

Entre las legislaciones nacionales propias del ámbito iberoamericano la legislación de Brasil fue pionera en la configuración de mecanismos de protección jurisdiccional de los intereses transindividuales, conocidos como intereses colectivos e intereses difusos ${ }^{2}$. Fruto de lo anterior, la normativa

1 En adelante, por comodidad de léxico, utilizaremos la expresión Código Modelo para referirnos al Código Modelo de Procesos Colectivos para Iberoamérica.

2 Sobre las ventajas e inconvenientes de atribuir la protección de intereses transindividuales a autoridades judiciales o a autoridades administrativas, con propuestas de complementariedad de ambos sistemas de protección cfr. ORTELLS RAMOS., M., "Protección de intereses 
brasileña influyó en el Código Modelo de Proceso Civil para Iberoamérica, así como en la actividad legislativa de otros ordenamientos iberoamericanos, lo que dio lugar al nacimiento de normas muy variadas y distintas sobre la tutela de los intereses colectivos y difusos en los diferentes países.

Sin embargo, esas regulaciones nacionales sobre la protección jurisdiccional de los intereses colectivos y difusos en Iberoamérica eran muy heterogéneas, lo que motivó en 2002 en el ámbito del Instituto Iberoamericano de Derecho Procesal el surgimiento de la idea de elaborar un Código Modelo de Procesos Colectivos para Iberoamérica, que sirviera de modelo a tener en cuenta en la actividad de producción legislativa de los distintos países iberoamericanos. Dicho Código Modelo, tras diversos estudios, trabajos y propuestas de perfeccionamiento, fue aprobado en Caracas en octubre de 2004 por la Asamblea General del Instituto Iberoamericano de Derecho Procesal.

Este Código Modelo presenta el mérito de ofrecer una regulación de la protección judicial de derechos o intereses transindividuales de carácter general, y no limitada a los que pueden resultar afectados en un ámbito determinado (consumo, medio ambiente, etc.). Dicha configuración normativa se realiza atendiendo a dos grandes categorías de intereses transindividuales, la categoría de intereses difusos -en la que se incluyen también los intereses colectivos ${ }^{3}-\mathrm{y}$ la categoría de intereses individuales homogéneos.

Así, al establecer el ámbito de aplicación del Código Modelo (art. 1 CMPCI), se dispone que la acción colectiva será ejercida para formular pretensiones de tutela de dos clases de intereses o derechos: los intereses o derechos difusos, y los derechos o intereses individuales homogéneos. Los intereses o derechos difusos los define como "los supraindividuales, de naturaleza indivisible, de que sea titular un grupo, categoría o clase de personas ligadas por circunstancias de hecho o vinculadas entre sí o con la parte contraria por una relación jurídica base". Mientras que los derechos o intereses individuales homogéneos los define como "el conjunto de derechos subjetivos individuales, provenientes de origen común, de que sean titulares los miembros de un grupo, categoría o clase".

Por lo tanto, los intereses o derechos difusos son supraindividuales y de naturaleza indivisible, ya que su titular es un grupo, categoría o clase de

jurídicos supraindividuales: actuación de las Administraciones Públicas, justicia civil y combinación de sistemas de protección”, Revista Ius et praxis, Chile, año 17, núm. 2, 2011, pp. 419-481.

3 Cfr. Apartado 6 de la Exposición de Motivos del Código Modelo y GIANNINI, L. J., La tutela colectiva de los intereses individuales homogéneos, Argentina, 2010, p. 169. 
personas ligadas -ya sea entre sí o con la parte contraria- por circunstancias de hecho o por una relación jurídica base.

En cambio, los derechos o intereses individuales homogéneos son derechos subjetivos individuales -no supraindividuales- y de naturaleza divisible ${ }^{4}$, procedentes de un origen común, y sus titulares son los miembros de un grupo, categoría o clase, y no el grupo, categoría o clase en cuanto tal ${ }^{5}$.

\section{LEGITIMACIÓN}

El Código Modelo, después de establecer la clasificación de los derechos e intereses (difusos e individuales homogéneos) a cuya protección judicial se puede proceder a través del ejercicio de la acción colectiva (art. 1 CMPCI), regula la legitimación activa para su ejercicio de modo abierto, con el objetivo de que la configuración normativa que efectúa sea compatible con la regulación de los distintos ordenamientos jurídicos de Iberoamérica.

Así, se reconoce legitimación activa (art. 3 CMPCI) para el ejercicio de la acción colectiva a toda persona física (I); a cualquier miembro del grupo, categoría o clase (II); al Ministerio Público, al Defensor del Pueblo y a la Defensoría Pública (III); a las personas jurídicas de derecho público interno (IV); a las entidades y órganos de la Administración Pública, directa o indirecta, aún sin personalidad jurídica, destinados a la defensa de derechos e intereses protegidos en el Código Modelo (V); a las entidades sindicales (VI); a las asociaciones legalmente constituidas desde por lo menos un año, que incluyan entre sus fines institucionales la defensa de los intereses y derechos protegidos en el Código Modelo (VII) ${ }^{6}$; y a los partidos políticos (VIII).

Sin embargo, en mi opinión, no se regula con la claridad deseable las clases de intereses (difusos y/o individuales homogéneos) que están legitimados para defender en juicio los distintos sujetos legitimados activamente. En principio, podría pensarse que los diferentes sujetos están legitimados para solicitar la tutela judicial, tanto de intereses difusos como de intereses individuales homogéneos, pues se les reconoce legitimación para el ejercicio de la

$4 \quad$ Cfr. párrafo séptimo del apartado 6 de la Exposición de Motivos del Código Modelo

5 Una excelente e ilustrativa exposición sobre analogías y diferencias entre las distintas clases de intereses transindividuales puede verse en GIDI, A., Las acciones colectivas y la tutela de los derechos difusos, colectivos e individuales en Brasil (Un modelo para países de derecho civil), México, 2004, pp. 98-99.

6 No obstante, según el art. $3^{\circ}$, Par. $1^{\circ} \mathrm{CMPCI}$, "el requisito de la preconstitución puede ser dispensado por el juez, cuando haya manifiesto interés social evidenciado por la dimensión o característica del daño, o por la relevancia del bien jurídico a ser protegido". 
acción colectiva y mediante ésta se puede solicitar la tutela de las dos clases de derechos e intereses.

Ahora bien, la duda se suscita porque en el Código Modelo, en unos casos, sólo se menciona la legitimación para solicitar la tutela de intereses difusos (I); en otros, se reconoce explícitamente la legitimación para la defensa de intereses difusos, así como para la defensa de intereses individuales homogéneos (II); en otros casos, o no se especifica ninguna categoría de intereses (III y IV), o se especifican intereses no calificados como difusos o individuales homogéneos (VI y VIII), o se refieren de forma genérica a los derechos e intereses protegidos en el Código Modelo (V y VII).

Por otra parte, la regulación extensa de la legitimación conduce también a que a los diversos legitimados activos se les reconoce una legitimación concurrente y autónoma, lo que puede motivar que varios de ellos intervengan en calidad de actores o demandantes en un mismo proceso, provocando una situación de litisconsorcio activo, si bien de carácter voluntario, pues es facultad de los distintos legitimados activos ejercer la acción o no, con la salvedad del Ministerio Público, el cual, si no ejercita la acción ni interviene originariamente como parte, en caso de que exista interés social relevante debe actuar necesariamente como fiscal de la ley (art. 3, Pár. $3^{\circ}$ y $4^{\circ} \mathrm{CMPCI}$ ).

En contraste con el carácter abierto de la configuración normativa de la legitimación activa en el Código Modelo, se establece un filtro que limita la inicial amplitud, en cuanto que establece el requisito de la representatividad adecuada respecto de cualquier legitimado que formule la demanda (art. 2 . I CMPCI), requisito cuya concurrencia debe apreciar el juez, atendiendo a los criterios orientativos que a título orientativo - no constituyen una lista cerrada- contiene el Código Modelo ${ }^{7}$.

No obstante, se realiza un esfuerzo para que la falta de concurrencia de dicho requisito en el actor, o el desistimiento o renuncia de éste, no conduzcan a la falta de tutela judicial de los derechos e intereses protegidos en el Código. Así, con dicha finalidad se dispone que en dichos casos el juez pueda llamar al proceso a otros legitimados activos por si éstos deciden voluntariamente asumir la titularidad de la acción.

Según el art. $2^{\circ}$, Par $2^{\circ}$ CMPCI, los criterios que debe ponderar el juez a los efectos de determinar la adecuada representatividad del demandante son, entre otros, la credibilidad, capacidad, prestigio y experiencia del legitimado; sus antecedentes en la protección judicial y extrajudicial de los intereses o derechos de los miembros del grupo, categoría o clase; su conducta en otros procesos colectivos; la coincidencia entre los intereses de los miembros del grupo, categoría o clase y el objeto de la demanda; y el tiempo de constitución de la asociación y la representatividad de ésta o de la persona física respecto del grupo, categoría o clase. 
Por último, no estaría de más señalar que la completa regulación del Código Modelo contempla incluso, a través de una norma que parece aludir tanto a la capacidad para ser parte demandada como a la legitimación pasiva, el ejercicio de una acción colectiva contra un grupo, categoría o clase, aceptando que pueda formularse respecto de esa clase de demandado cualquier tipo de pretensión, siempre que se den unos requisitos: que se dirija contra una colectividad organizada o que tenga representante adecuado, que el bien jurídico a tutelar sea supraindividual y que esté revestido de interés social (art. $35 \mathrm{CMPCI}$ ).

\section{ACCIONES EJERCITABLES EN DEFENSA DE DERECHOS E INTERESES SUPRAINDIVIDUALES E INDIVIDUALES HOMOGÉNEOS}

El Código Modelo tiene una clara aspiración a la absoluta eficacia de la protección jurisdiccional que pueda alcanzarse en los procesos dirigidos a la protección de intereses supraindividuales, y a tal fin delimita las acciones que pueden ejercitarse en tutela de esos intereses mediante diferentes técnicas.

Por una parte, a través de una enumeración orientativa de las clases de obligaciones cuyo cumplimiento puede perseguirse mediante el ejercicio de la acción colectiva: obligaciones de hacer y de no hacer (art. $6 \mathrm{CMPCI}$ ), obligaciones de dar (art. 7 CMPCI) y obligación de indemnizar, última obligación impuesta tanto para el supuesto de lesión de derechos supraindividuales (art. 8 CMPCI), como para el caso de violación de derechos individuales homogéneos (art. 20 CMPCI).

Por otra parte, mediante la introducción de una cláusula general, según la cual resultan admisibles todas las acciones que resulten idóneas para obtener la adecuada y efectiva tutela de los derechos e intereses protegidos por el Código Modelo (art. 4 CMPCI).

Por último, a través de la instauración de una modalidad de tutela jurisdiccional anticipada, que puede anticipar, total o parcialmente, los efectos de la tutela solicitada en la demanda y que puede llegar a convertirse en definitiva, total o parcialmente, si el demandado no formula oposición después de la oportunidad del contradictorio (art. 5 CMPCI).

Con relación a la primera de las técnicas aludidas, el Código Modelo, en aras a la efectividad de la tutela judicial solicitada, es claro que consagra la preferencia por la ejecución en forma específica de todas las sentencias de condena y, en especial, de las sentencias estimatorias de la acción inhibitoria, y con dicha finalidad establece diferentes medidas que pueden ser acordadas para lograr la ejecución en forma específica de esa clase de sentencias, como la 
multa al demandado por cada día de incumplimiento, las órdenes de búsqueda o aprehensión, la demolición de obras y el requerimiento de auxilio a la fuerza policial (art. 6 CMPCI).

Esa misma preferencia de la ejecución en forma específica se establece también respecto de las sentencias de condena a entregar una cosa, determinada o indeterminada (art. 7 CMPCI), limitando a casos residuales la sustitución de la ejecución de la obligación originaria por la obligación de indemnizar daños y perjuicios, bien cuando por ella optare el actor, o bien cuando la tutela en forma específica sea imposible (art. 6 CMPCI)

Por último, se contempla igualmente la posibilidad de ejercer acciones de condena pecuniaria -la acción indemnizatoria-, acción prevista tanto para el supuesto de lesión de intereses supraindividuales (art. $8 \mathrm{CMPCI}$ ), como para el caso de vulneración de derechos individuales homogéneos (art. 20 CMPCI). Cuando la acción se ejercita por violación de intereses supraindividuales esa acción se dirige a la reparación de los daños causados al bien indivisiblemente considerado, ingresándose la indemnización que se obtenga en un Fondo de los Derechos Difusos e Individuales Homogéneos, cuyos recursos serán destinados a la reconstitución de los bienes lesionados, a minimizar la lesión o a evitar que se repita (art. $8 \mathrm{CMPCI}$ ).

Por el contrario, cuando la acción de condena pecuniaria tiene su origen en la lesión de derechos individuales homogéneos dicha acción tiene por objeto la indemnización por los daños individualmente sufridos por los distintos miembros del grupo, categoría o clase de personas, es decir, la lesión de derechos individuales homogéneos (art. $20 \mathrm{CMPCI}$ ), cuya reparación tiene, además, carácter preferente respecto de la acción prevista con relación a bienes supraindividuales (art. $28 \mathrm{CMPCI}$ ).

\section{Competencia}

El Código Modelo establece una norma sobre la competencia territorial que se fija en función de la extensión o alcance del daño a los intereses difusos o individuales homogéneo. Así, se dispone que, cuando el daño sea de ámbito local, la competencia territorial corresponderá al juez del lugar donde hubiere ocurrido o pudiere ocurrir el daño. Por el contrario, cuando el alcance del daño sea mayor, concretamente cuando los daños sean de ámbito regional o nacional, la competencia se atribuye al juez de la capital (art. 9 CMPCI).

Así mismo, se establece la aspiración de que los procesos colectivos sean enjuiciados por órganos judiciales integrados por magistrados especializados (art. $40 \mathrm{CMPCI})$. 


\section{REQUISITOS DE LA DEMANDA COLECTIVA}

El Código Modelo no impone actuaciones previas a la presentación de la demanda colectiva, pero sí establece unos requisitos especiales para ella (art. 2 CMPCI). El primero consiste en que el legitimado activo que interponga la demanda debe poseer una adecuada representatividad, requisito que el juez puede analizar en cualquier tiempo y grado del procedimiento, atendiendo a los criterios orientativos que establece el propio Código Modelo (art. 2, Par. $2^{\circ}$ ).

En segundo lugar, es necesario que la tutela colectiva solicitada en la demanda tenga relevancia social, concepto jurídico indeterminado ${ }^{8}$ que habrá que especificar atendiendo a la naturaleza del bien jurídico afectado, a las características de la lesión, o al elevado número de perjudicados.

En tercer lugar, un requisito específico y adicional, relativo a las demandas en las que se solicite la tutela judicial de derechos individuales homogéneos, es la demostración del predominio de las cuestiones comunes sobre las individuales y de la utilidad de la tutela colectiva en el supuesto concreto.

\section{Reglas PROCESALES DEL PROCESO DE DECLARACIÓN (CONOCIMIENTO)}

\subsection{Procesos colectivos en general}

El proceso de declaración en el que se ejercite la acción colectiva tiene una serie de especialidades procesales que, brevemente, enunciamos:

a) Flexibilidad en la configuración del objeto del proceso, lo que determina que el petitum y la causa petendi se interpreten extensivamente, admitiendo que puedan alterarse tanto el objeto de la demanda como su causa de pedir, así como que esa alteración del objeto del proceso pueda darse en cualquier tiempo y grado de jurisdicción (art. $10 \mathrm{CMPCI}$ ).

b) Celebración de una audiencia preliminar, cuya finalidad es alcanzar una solución amistosa del conflicto y, si ésta no es posible, tomar medidas relativas a la continuación del proceso: decidir si el proceso debe seguir en forma colectiva; acordar la separación en procesos colectivos distintos, por una parte, los que se sigan para la defensa de intereses difusos, y por otra los dirigidos a la protección de derechos individuales homogéneos; decidir cuestiones procesales pendientes; fijar los puntos controvertidos y las pruebas

$8 \quad$ GIANNINI, L. J, La tutela colectiva..., Op. cit., p. 170, advierte del peligro que para la efectividad de la tutela jurisdiccional colectiva puede entrañar esa indeterminación. 
admisibles, orientando a las partes sobre la distribución de la carga de la prueba (art. $11 \mathrm{CMPCI}$ ).

c) En materia de prueba, se consideran admisibles todos los medios de prueba obtenidos por medios lícitos, admitiendo así mismo que la prueba pueda también ser acordada de oficio por el juez, siempre que se garantice la contradicción. Por otro lado, la distribución de la carga de la prueba se efectúa atendiendo al principio de facilidad probatoria (art. $12 \mathrm{CMPCI}$ ).

d) Si no fuere necesaria la práctica de prueba, el juez decidirá directamente el fondo de la demanda, lo cual podrá hacer total o parcialmente, es decir, solo respecto de la parte de ésta no necesitada de prueba (art. $13 \mathrm{CMPCI})$

e) En materia de costas y gastos procesales, el criterio de imposición se modula en función de la parte de que se trate. Respecto de la parte demandada, rige un criterio objetivo, siendo condenada dicha parte a sufragar los gastos procesales si es vencida. Por el contrario, respecto de los actores, rige el criterio subjetivo, siendo condenados a dichos gastos, si se apreciase su mala fe (art. 15 CMPCI).

f) El juez debe dar tramitación preferente a los procesos colectivos siempre que concurra manifiesto interés social, el cual se determinará en función de la dimensión del daño o de la relevancia del bien jurídico a proteger (art. 16 CMPCI).

g) En los procesos colectivos la citación válida interrumpe el plazo de prescripción, tanto de las pretensiones individuales como de las transindividuales, directa o indirectamente relacionadas con la controversia, y retrotrae sus efectos a la fecha de la presentación de la demanda (art. 17 CMPCI).

h) El recurso de apelación contra la sentencia definitiva con carácter general se admitirá solo con efecto devolutivo, si bien excepcionalmente el juez podrá admitir el recurso con efecto suspensivo cuando la fundamentación sea relevante y pueda resultar para la parte una lesión grave y de difícil reparación (art. $18 \mathrm{CMPCI})$.

\subsection{Procesos colectivos en defensa de intereses individuales homogéneos}

El Código Modelo también establece unas reglas especiales de aplicación a los procesos colectivos en los que se solicite el resarcimiento colectivo de los daños individuales sufridos. En este caso, la demanda podrá ser presentada por cualquiera de los legitimados para ejercitar la acción colectiva (art. $3 \mathrm{CMPCI}$ ), en nombre propio y en interés de las víctimas (art. $20 \mathrm{CMPCI}$ ). 
Con carácter general, no es necesario hacer en la demanda una relación de los miembros del grupo, clase o categoría cuyos daños individuales se reclaman, porque, salvo apreciación judicial en contrario, el momento ordinario para la determinación de las víctimas es el de la liquidación o ejecución de lo juzgado (art. $20 \mathrm{CMPCI}$ ).

Sin embargo, sí se arbitran mecanismos para dar publicidad al proceso colectivo con la finalidad de que los interesados puedan intervenir en el proceso, mecanismos de publicidad que se proyectan tanto sobre la demanda como sobre la sentencia dictada. Respecto de la demanda, la publicidad se articula mediante la publicación de edictos en el tablón de anuncios del órgano judicial, así como mediante la notificación a los órganos y entidades de defensa de los derechos e intereses protegidos en el Código Modelo. Por el contrario, la publicidad de la sentencia se realiza tanto mediante los dos mecanismos anteriores, como, adicionalmente, mediante su difusión a través de medios de comunicación social a costa del demandado (art. $21 \mathrm{CMPCI}$ ).

En un principio llama la atención -por el posible resultado de indefensión que pudiera producirse- que la publicidad de la demanda colectiva sea tan solo con el fin de que los interesados puedan intervenir en el proceso colectivo como asistentes o coadyuvantes, y de que se les impida a los intervinientes discutir en el proceso colectivo de su conocimiento sus pretensiones individuales (art. $21 \mathrm{CMPCI}$ ).

Sin embargo, lo anterior no es más que un mecanismo para conseguir una mayor agilidad del proceso colectivo de declaración (de conocimiento), ya que la posibilidad de contradicción sobre las pretensiones individuales no se excluye, sino que se difiere, pues el miembro del grupo que no esté de acuerdo con el monto de la indemnización individual o con la fórmula para su cálculo establecidos en la sentencia colectiva, podrá mostrar su oposición formulando una pretensión individual de liquidación (art. 22. Pár. $3^{\circ} \mathrm{CMPCI}$ ).

Por último, se establecen distintas reglas relativas a la determinación del contenido de la sentencia de condena a responsabilidad civil. En primer lugar, si es posible, se determinará en la propia sentencia colectiva el monto de la indemnización individual debida a cada miembro del grupo. En segundo lugar, si el valor de los daños individuales sufridos por los miembros del grupo es uniforme, prevalentemente uniforme o puede ser reducido a una fórmula matemática, la sentencia indicará el valor o la fórmula de cálculo de la indemnización individual. En tercer lugar, cuando no sea posible ninguno de los supuestos anteriores, podrá dictarse sentencia de condena genérica, que se limitará a fijar la responsabilidad del demandado por los daños causados y 
su deber de indemnizar, supuesto en el que deberá procederse a la liquidación con carácter previo a la ejecución (art. 22 CMPCI).

\section{REGLAS PROCESALES SOBRE LIQUIDACIÓN Y EJECUCIÓN DE LA SENTENCIA}

El Código Modelo contiene normas sobre liquidación y ejecución de las sentencias de condena de dos clases. Por una parte, contiene normas que son de aplicación a la liquidación y ejecución de las sentencias de condena dictadas en los procesos colectivos en general. Por otra parte, establece otras normas que solo resultan aplicables a la liquidación y ejecución de las sentencias de condena dictadas en los procesos colectivos dirigidos a la defensa de intereses o derechos individuales homogéneos.

Respecto de las normas que son de aplicación a la liquidación y ejecución de las sentencias de condena dictadas en los procesos colectivos en general, por una parte y presupuesta la legitimación del demandante del proceso de declaración (conocimiento), se amplía la legitimación si éste no solicita la liquidación o ejecución de la sentencia de condena, una vez transcurridos 60 días desde la firmeza de ésta.

Así, en caso de pasividad o inactividad del demandante inicial, y con el fin de potenciar la efectividad de las sentencias que recaen en los procesos colectivos, se establece el deber de solicitarla del Ministerio Fiscal, en el caso de que concurra un interés social relevante, y la facultad de instarla de los demás legitimados (art. 14 CMPCI).

Por otra parte, a fin de reforzar igualmente la efectividad de la tutela judicial que puede otorgarse a través de los procesos colectivos se admite la ejecución provisional de la sentencia por cuenta y riesgo del ejecutante. Sin embargo, la ejecución provisional no se configura como un derecho absoluto del ejecutante, pues se prevé expresamente la posibilidad de suspensión de esa ejecución, previa instancia del ejecutado, cuando la ejecución pueda causar a éste una lesión grave o de difícil reparación (art. $19 \mathrm{CMPCI}$ ).

Respecto de las normas aplicables de forma limitada a la liquidación y ejecución de las sentencias de condena dictadas en los procesos colectivos dirigidos a la defensa de intereses o derechos individuales homogéneos, se reconocen dos clases de ejecución. Por una parte, se reconoce una ejecución individual -que pueden instar tanto la víctima como los legitimados para la acción colectiva(art. 23 CMPCI). Por otra parte, también se contempla una ejecución colectiva (art. 24 CMPCI), la cual debe ser promovida por un sujeto legitimado para la 
acción colectiva y que abarcará las indemnizaciones correspondientes a pluralidad de víctimas.

En ambos casos, salvo en el supuesto de sentencia líquida (art. 22. Pár. $1^{\circ}$ CMPCI), previamente a la ejecución debe procederse a la liquidación de la sentencia de condena mediante la prueba de los daños individuales, de su nexo de causalidad con el objeto mediato del proceso colectivo y del monto de la indemnización (arts. 23 y 24 CMPCI). La competencia para la ejecución se atribuye al juez que hubiere dictado la sentencia de condena, en caso de ejecución colectiva, y a dicho juez o al juez del domicilio del ejecutante, en el caso de ejecución individual (arts. 23 y 25 CMPCI) ${ }^{9}$, debiendo acordar el juez que el pago de las indemnizaciones se haga personalmente a los beneficiarios (art. 26 CMPCI).

No obstante lo anterior, si en el plazo de una año no comparecen un número de interesados representativo y compatible con la gravedad del daño, cualquier legitimado con legitimación colectiva (art. 3 CMPCI) podrá solicitar una indemnización colectiva, cuyo valor debe fijarse en atención al daño globalmente causado y que podrá acreditarse mediante todas las pruebas admisibles en derecho (art. $27 \mathrm{CMPCI})^{10}$.

No establece el Código Modelo cuál será el destino de esa indemnización global, aunque podría concluirse que en este supuesto la indemnización deberá ser vertida al Fondo de los Derechos Difusos e Individuales Homogéneo ${ }^{11}$, mediante una interpretación conjunta de los arts. 8, 27 y 28 CMPCI.

Por lo demás, se establecen normas de prevalencia entre las diversas indemnizaciones que puedan resultar procedentes en un caso. Así, se determina la preferencia de las indemnizaciones por perjuicios individuales respecto de los créditos derivados de la ejecución por sustitución de las sentencias de condena a un hacer o no hacer, así como respecto de las cantidades que deban destinarse al Fondo (art. $28 \mathrm{CMPCI}$ ).

9 Como advierte GIANNINI, L. J, La tutela colectiva..., Op. cit., p. 177, este foro optativo tiene la finalidad de facilitar el acceso a la justicia del afectado, a quien podría no compensarle económicamente trasladarse al lugar donde se dictó la sentencia de condena genérica para hacer efectiva la satisfacción de su derecho individual homogéneo.

10 Este precepto suscita distintas cuestiones. Además de la indeterminación de ciertos conceptos utilizados (comparecencia de interesados "en número representativo y compatible con la gravedad del daño”), destaca la indefinición del día inicial para el cómputo del plazo de un año, día inicial que, por analogía a lo dispuesto en otro precepto (art. 14), puede considerarse el día de la firmeza de la sentencia colectiva.

11 En este sentido, GIANNINI, L. J., La tutela colectiva..., Op. cit., p. 187. 


\section{RELACIONES ENTRE ACCIONES COLECTIVAS Y ENTRE ACCIONES COLECTIVAS Y ACCIONES INDIVIDUALES}

\subsection{Acumulación de procesos y litispendencia}

Este Código contiene normas sobre la litispendencia, considerando la que podría considerase producida tanto en el caso de ejercicio de acciones colectivas como en el caso de que se ejerzan acciones individuales.

$\mathrm{Si}$ se interpusieren varias acciones colectivas, debe tenerse en cuenta que una vez pendiente un proceso como consecuencia del ejercicio de una acción colectiva, la litispendencia impide el inicio de un segundo proceso en el que se ejercite otra acción colectiva sobre el mismo bien jurídico, aunque sean diferentes los legitimados activos, o las causas de pedir (art. $30 \mathrm{CMPCI}$ ).

Sin embargo, si la segunda acción colectiva no versa sobre el mismo bien jurídico, pero guarda conexión con él, la consecuencia no será evitar el segundo proceso, sino posibilitar que se acumule al primer proceso a favor del juez que conoce de éste (art. 29 CMPCI).

También contempla el Código Modelo la posibilidad de que puedan concurrir el ejercicio de una acción colectiva y el ejercicio de acciones individuales. En concreto, respecto de la relación entre la acción colectiva y las acciones individuales, se establece que, en principio, la existencia de un proceso colectivo no impide el inicio de nuevos procesos en los que se ejerciten acciones individuales.

Sin embargo, se matiza que en estos supuestos los efectos de cosa juzgada del proceso colectivo no beneficiarán a los actores en los procesos individuales, si estos, una vez tengan conocimiento del proceso colectivo, no solicitan la suspensión del proceso individual (art. $31 \mathrm{CMPCI}$ ).

Por último, también se establece que la existencia de diversos procesos individuales dirigidos contra el mismo demandado con el mismo fundamento no impide el inicio de un proceso colectivo.

No obstante, también se precisa que en este supuesto, si los actores de los procesos individuales quieren beneficiarse de la cosa juzgada del proceso colectivo, deben solicitar la suspensión de los procesos individuales (art. $32 \mathrm{CMPCI}$ ).

Respecto de estos supuestos de concurrencia de ejercicio de acciones colectivas con acciones individuales deben hacerse dos consideraciones. La primera, más limitada, es relativa al segundo supuesto -inicio de proceso colectivo posterior a procesos individuales ya pendiente-, debiendo tenerse en cuenta que, aunque no se establezca expresamente en este caso, presupuesto de que 
los actores individuales no puedan beneficiarse de la cosa juzgada del proceso colectivo será que dichos actores tengan conocimiento del proceso colectivo, pues sin dicho conocimiento resulta irrazonable atribuirles la carga de solicitar la suspensión de sus proceso individuales.

La segunda consideración es más general, afectando a ambos supuestos de concurrencia de ejercicio de acciones colectivas y de acciones individuales, y es que en dicha regulación existe una adecuada armonización del alcance de cosa juzgada de las sentencias dictadas en los procesos colectivos con el principio de libertad que debe regir cuando del ejercicio de acciones estrictamente individuales se trate.

\subsection{Cosa juzgada}

El régimen de la eficacia de cosa juzgada de la sentencia dictada en el proceso colectivo se establece sobre la base de una cláusula general, que es completada con otras disposiciones específicas en atención a que el proceso colectivo se dirija a la tutela de intereses difusos, o a la protección de intereses individuales homogéneos; regulación que, a mi juicio, presenta cierto grado de confusión.

Como cláusula general se establece que en los procesos colectivos el régimen general de la cosa juzgada es la eficacia de la sentencia erga omnes ${ }^{12}$, sin distinguir inicialmente en función de que la sentencia sea de estimación de la pretensión, o de desestimación de ésta. La única excepción se establece para los casos en los que se aprecie la improcedencia de la pretensión y ésta se funde en la insuficiencia de pruebas, hipótesis en la que se admite una segunda demanda fundada en nuevas pruebas en el plazo de dos años contado desde el conocimiento de aquellas (art. 33, I y Pár. $\left.1^{\circ}\right)^{13}$.

Sin embargo, las disposiciones específicas relativas a la eficacia de cosa juzgada, según se trate de sentencias dictadas en proceso dirigidos a la tutela de intereses difusos, o de sentencias dictadas en procesos dirigidos a la protección de derechos individuales homogéneos, parece que establecen un régimen de eficacia de la cosa juzgada secundum eventum litis en ambos casos, al menos, en los que a las acciones de indemnización se refiere: extensible a los no litigantes individuales en lo que les favorece, no en lo que les perjudica.

12 Como advierte GIDI, A., Las acciones colectivas..., Op. cit., pp. 98-99, el carácter erga omnes de la eficacia de cosa juzgada constituye el elemento esencial del proceso colectivo.

13 En sentido diferente, GIANNINI, L. J., La tutela colectiva..., Op. cit., p. 170, considera que la eficacia erga omnes de la sentencia colectiva es aplicable tanto a los intereses difusos, como a los intereses individuales homogéneos. 
Así, respecto de las sentencias dictadas en los procesos de tutela de intereses o derechos difusos, parece claro que se establece un régimen de eficacia de la cosa juzgada secundum eventum litis, ya que dispone que los efectos de la cosa juzgada "no perjudicarán las acciones de indemnización por daños personalmente sufridos, propuestas individualmente o en la forma prevista en este Código, pero si hubiera sido declarado procedente el pedido, tales efectos beneficiarán a las víctimas y a sus sucesores quienes podrán solicitar la liquidación y la ejecución en los términos de los artículos 22 a 24" (art. 33, Par. 3).

Por otra parte, respecto del régimen de eficacia de cosa juzgada de las sentencias dictadas en procesos dirigidos a la tutela de intereses individuales homogéneos, se dispone que "tratándose de intereses o derechos individuales homogéneos, en caso de rechazo de la pretensión, los interesados podrán deducir la acción de indemnización a título individual (art. 33. Pár. $2^{\circ}$ ).

De una interpretación conjunta de esta disposición y de la cláusula general establecida para las sentencias dictadas en los procesos colectivos (art. 33, I y Pár. $1^{\circ}$ ) parece deducirse -aunque sería conveniente una mayor claridad al respecto- que en el caso de que el proceso colectivo se dirija a la tutela de intereses individuales homogéneos, también se establece un sistema de eficacia de la cosa juzgada secundum eventum litis: es decir, en caso de sentencia favorable, la cosa juzgada actúa erga omnes, beneficiando a todos los miembros del grupo, lo que se establece de modo expreso (art. 33, I y Pár. $1^{\circ}$ ); por el contrario, en caso de dictarse una sentencia desfavorable, la cosa juzgada sólo alcanza a los legitimados para el ejercicio de las acciones colectivas, no a los legitimados para el ejercicio de acciones individuales, que pueden oponerse a la cosa juzgada, promoviendo su acción individual, lo que no se establece expresamente pero puede deducirse de la norma general (art. 33. Pár. $2^{\circ}$ ).

Por último, también se regula la eficacia de cosa juzgada de la sentencia dictada como consecuencia del ejercicio de acciones contra el grupo, categoría o clase. Si se trata de intereses o derechos difusos, la cosa juzgada tiene eficacia erga omnes, vinculando a los miembros del grupo, categoría o clase (art. 36). En cambio, si se trata de intereses o derechos individuales homogéneos, se establece un régimen de eficacia de la cosa juzgada secundum eventum litis en beneficio de los miembros del grupo, categoría o clase (art. 37).

\section{Conclusiones}

Para finalizar este trabajo y tras la exposición de las anteriores consideraciones, conviene extraer algunas conclusiones sobre la regulación de los procesos colectivos del Código Modelo de estos procesos para Iberoamérica. 
Por lo que respecta a la regulación de la legitimación en el Código Modelo, a mi juicio, resulta positiva la amplia configuración de la legitimación activa para el ejercicio de la acción colectiva (art. $3 \mathrm{CMPCI}$ ), matizada mediante el requisito de la representatividad adecuada exigible respecto de cualquier legitimado que formule la demanda (art. 2. I CMPCI). Sin embargo, dicha regulación resulta mejorable, en la medida en que, en mi opinión, no se regula con la claridad deseable las clases de intereses (difusos y/o individuales homogéneos) que están legitimados para defender en juicio cada uno de los distintos sujetos legitimados activamente.

También debe considerarse acertada la técnica de determinación de las acciones ejercitables en defensa de derechos e intereses supraindividuales e individuales homogéneos utilizada en el Código Modelo. Éste tiene una clara aspiración a la absoluta eficacia de la protección jurisdiccional que pueda alcanzarse en los procesos dirigidos a la protección de intereses supraindividuales, y a tal fin delimita las acciones que pueden ejercitarse en tutela de esos intereses mediante diferentes técnicas.

Por una parte, mediante disposiciones especiales relativas a dos extremos. Por un lado, a través de una enumeración ejemplificativa de las clases de obligaciones cuyo cumplimiento puede perseguirse mediante el ejercicio de la acción colectiva: obligaciones de hacer y de no hacer (art. $6 \mathrm{CMPCI}$ ), obligaciones de dar (art. 7 CMPCI) y obligación de indemnizar, última obligación impuesta tanto para el supuesto de lesión de derechos supraindividuales (art. 8 CMPCI), como para el caso de violación de derechos individuales homogéneos (art. 20 CMPCI).

Y, por otro lado, mediante la especificación de la admisibilidad de una modalidad de tutela jurisdiccional anticipada, que permita adelantar todos o algunos de los efectos de la tutela solicitada en el proceso principal, con un carácter, en principio provisional, que no obstante puede llegar a convertirse en definitivo (art. 5 CMPCI).

Pero, además de esas disposiciones especiales, se introduce una cláusula general, según la cual resultan admisibles todas las acciones que resulten idóneas para obtener la adecuada y efectiva tutela de los derechos e intereses protegidos por el Código Modelo (art. $4 \mathrm{CMPCI}$ ).

Por lo tanto, la técnica de delimitación en el Código Modelo de las acciones ejercitables para la protección de los intereses en él contemplados merece un juicio favorable, porque las disposiciones especiales sirven claramente para orientar sobre las distintas modalidades de tutela jurisdiccional que pueden solicitarse en estos procesos. 
Pero, además, la cláusula general constituye una suerte de norma de cierre del sistema de protección jurisdiccional, que evita que se produzcan lagunas normativas, al admitir cualesquiera acciones en las que concurran unos razonables requisitos: que sean aptas para obtener la adecuada y efectiva tutela de los derechos e intereses protegidos por el Código Modelo (art. 4 CMPCI).

Así mismo, con carácter general, resulta favorable la regulación en el Código Modelo de las normas procesales aplicables el proceso de declaración (conocimiento), tanto las aplicables a los procesos colectivos en general, como las adicionales aplicables a los procesos en los que se postula la defensa de intereses individuales homogéneos.

Respecto de las primeras es positiva la articulación de diferentes mecanismos tendentes a alcanzar la agilidad del proceso colectivo: la previsión de una audiencia preliminar con el fin de obtener la resolución anticipada del proceso o su ordenación para una más eficaz tramitación del mismo (art. $11 \mathrm{CMPCI}$ ), la admisibilidad de la resolución anticipada de la parte de la demanda no necesitada de prueba (art. $13 \mathrm{CMPCI}$ ), y el otorgamiento de carácter preferente a la tramitación de los procesos colectivos siempre que concurra manifiesto interés social (art. 16 CMPCI).

Así mismo, resulta acertada la armonía de las técnicas de flexibilización del proceso colectivo que puede requerir una adecuada protección de los intereses regulados en el Código Modelo con el respeto de principios esenciales del proceso. En este sentido, si bien se aprecia flexibilidad en la configuración del objeto del proceso -al permitir su alteración con amplitud-, o en la determinación de las formas de adopción de la práctica de los medios de prueba, al admitir que pueda ser acordada de oficio por el juez, ambas clases de actuación (alteración del objeto del proceso, o acuerdo de oficio de los medios de prueba) se supeditan a la salvaguarda del derecho de defensa o principio del contradictorio (arts. 10 y 12 CMPCI).

Por último, debe considerarse también adecuada la previsión de la incidencia del inicio del proceso colectivo sobre el plazo de prescripción de las acciones individuales y transindividuales (art. 17 CMPCI).

Respecto de las normas del proceso de declaración (conocimiento) aplicables a los procesos en los que se solicita la protección judicial de intereses individuales homogéneos, merece un juicio favorable la flexibilidad que preside la forma de determinación del contenido de la sentencia de condena a responsabilidad civil (art. $22 \mathrm{CMPCI}$ ), así como la utilización de pluralidad de técnicas para dar publicidad a la demanda y a la sentencia (art. $21 \mathrm{CMPCI}$ ), con el fin de posibilitar la intervención de los interesados, y si bien la inicial limitación de las posibilidades de contradicción pudiera parecer criticable desde la perspectiva 
de la protección del derecho de defensa, el fundamento de la crítica se desvanece cuando se aprecia que la plenitud del contradictorio de los interesados solo se difiere en aras de una mayor agilidad del proceso colectivo (art. 22. Pár. $3^{\circ}$ CMPCI).

También contiene el Código Modelos aplicables a la liquidación y ejecución de las sentencias de condena. Respecto de las sentencias dictadas en los procesos colectivos en general, resulta positivo, a fin de potenciar la efectividad de las sentencias que recaen en los procesos colectivos, que en caso de pasividad o inactividad del demandante inicial -que deje transcurrir 60 días desde la firmeza de la sentencia sin solicitar la liquidación o ejecución de la sentencia- se amplíe la legitimación para solicitar ésta mediante el establecimiento del deber de solicitarla del Ministerio Fiscal, en el caso de que concurra un interés social relevante, y de la facultad de instarla de los demás legitimados (art. 14 CMPCI).

Por otra parte, a fin de reforzar igualmente la efectividad de la tutela judicial que puede otorgarse a través de los procesos colectivos se admite la ejecución provisional de la sentencia por cuenta y riesgo del ejecutante. Sin embargo, la ejecución provisional no se configura como un derecho absoluto del ejecutante, pues se prevé expresamente la posibilidad de suspensión de esa ejecución, previa instancia del ejecutado, cuando la ejecución pueda causar a éste una lesión grave o de difícil reparación (art. 19 CMPCI).

También el Código Modelo presta atención a la efectividad de la tutela judicial respecto de las normas aplicables a la liquidación y ejecución de las sentencias de condena dictadas en los procesos colectivos dirigidos a la defensa de intereses o derechos individuales homogéneos. En efecto, ciertamente se reconocen dos clases de ejecución, ejecución individual y ejecución colectiva, restringiéndose en principio la legitimación para instar la segunda (art. 24 CMPCI).

No obstante lo anterior, con el fin de reforzar igualmente la efectividad de la tutela judicial que puede otorgarse a través de los procesos colectivos se establece que si en el plazo de una año no comparecen un número de interesados representativo y compatible con la gravedad del daño, cualquier legitimado con legitimación colectiva (art. $3 \mathrm{CMPCI}$ ) podrá solicitar una indemnización colectiva (art. $27 \mathrm{CMPCI}$ ).

Así mismo, resulta positivo que se prevean normas de prevalencia entre las diversas indemnizaciones que puedan resultar procedentes en un caso (art. 27 CMPCI). Con todo, a mi juicio, puede realizarse alguna propuesta de mejora, ya que no establece el Código Modelo cuál será el destino de la indemnización global, siendo conveniente que para una mayor seguridad jurídica así lo determine. 
El carácter completo de la regulación contenida en el Código Modelo conduce a que también se prevean las relaciones entre distintas acciones colectivas entre sí y entre acciones colectivas y acciones individuales. Por lo que se refiere a las primeras el Código Modelo diferencia con acierto el efecto procesal que debe tener el inicio de un segundo proceso colectivo, en función de que el objeto de éste sea idéntico al del primer proceso colectivo, en cuyo caso la litispendencia debería impedir un segundo proceso colectivo (art. $30 \mathrm{CMPCI}$ ), o de que el objeto del segundo proceso colectivo sea diferente, aunque conexo, del objeto del primer proceso colectivo, en cuyo caso el efecto jurídico adecuado sería la acumulación de procesos (art. $29 \mathrm{CMPCI})$.

Respecto de los supuestos de concurrencia de ejercicio de acciones colectivas con acciones individuales resulta de destacar en la regulación del Código Modelo la adecuada armonización del alcance de cosa juzgada de las sentencias dictadas en los procesos colectivos con el principio de libertad que debe regir cuando del ejercicio de acciones estrictamente individuales se trate.

Por último, la regulación del régimen de la eficacia de cosa juzgada de la sentencia dictada en el proceso colectivo - una cuestión esencial en la ordenación de esta materia- presenta aspectos claramente positivos, ponderando las distintas soluciones que a nivel doctrinal y legislativo se han propuesto al respecto (eficacia de la sentencia erga omnes, eficacia de la cosa juzgada secundum eventum litis). Sin embargo, existe algún aspecto mejorable. En este sentido, el régimen de la eficacia de cosa juzgada de la sentencia dictada en el proceso colectivo se establece sobre la base de una cláusula general, que es completada con otras disposiciones específicas en atención a que el proceso colectivo se dirija a la tutela de intereses difusos, o a la protección de intereses individuales homogéneos. A mi juicio, la articulación de la cláusula general con las disposiciones específicas presenta cierto grado de confusión, que convendría eliminar.

\section{REFERENCIAS}

ORTELLS RAMOS., M., "Protección de intereses jurídicos supraindividuales: actuación de las Administraciones Públicas, justicia civil y combinación de sistemas de protección", Revista Ius et praxis, Chile, año 17, núm. 2, 2011, pp. 419-481.

GIANNINI, L. J., La tutela colectiva de los intereses individuales homogéneos, Argentina, 2010, p. 169. 
GIDI, A., Las acciones colectivas y la tutela de los derechos difusos, colectivos e individuales en Brasil (Un modelo para países de derecho civil), México, 2004, pp. 98-99.

Exposición de Motivos del Código Modelo de Procesos Colectivos para Iberoamérica.

Código Modelo de Procesos Colectivos para Iberoamérica. 